doi: $10.15407 /$ ujpe61.09.0780

S. VOVDENKO,${ }^{1}$ I. DMITRUK, ${ }^{1}$ N. BEREZOVSKA, ${ }^{1}$ S. KUTOVYI, ${ }^{1}$

A. KALYUZHNYY, ${ }^{1}$ N. ZUBRILIN,${ }^{2}$ O. DOMBROVSKY ${ }^{2}$

1 Taras Shevchenko National University of Kyiv

(64/13, Volodymyrs'ka Str., Kyiv, 01601 Ukraine)

2 Institute of Physics, Nat. Acad. of Sci. of Ukraine

(46, Prosp. Nauky, Kyiv 03680, Ukraine)

\title{
LASER-INDUCED QUASIPERIODIC METAL STRUCTURES FOR EFFICIENT EXCITATION OF SURFACE PLASMONS ${ }^{1}$
}

\section{Introduction}

Modification of the surface topology of substances under the influence of laser radiation is of importance for fundamental and applied purposes of researches. Metals are the typical materials for the development of self-organized surface structures. Laserinduced periodic structures on metal surfaces have advantages due to their capability to support collective electron oscillations or plasmons, which are involved in a number of effects, particularly the local enhancement and the strong confinement of an electromagnetic field on length scales much smaller than the optical diffraction limit. Such unique properties can provide many important applications such as surface enhanced Raman spectroscopy (SERS), active plasmonic devices, biosensors, etc.

(C) S. VOVDENKO, I. DMITRUK, N. BEREZOVSKA, S. KUTOVYI, A. KALYUZHNYY, N. ZUBRILIN,

O. DOMBROVSKY, 2016
Raman spectra are used to obtain information about the structure of matter, in particular about the elementary vibrations. Typically, the cross sections of Raman scattering are very small, namely of the order about $10^{-30} \mathrm{~cm}^{2}$. Nevertheless, in some specific cases, they demonstrate a surprising enhancement. Rough metal surfaces are used to increase the intensity of the Raman spectra of substances [1]. For some substances deposited on such substrates, an increase of the Raman signal intensity by $10^{6}-10^{7}$ times has been observed. Essentially large Raman cross sections per molecule of the order of at least $10^{-16} \mathrm{~cm}^{2}$ have been achieved [2]. Moreover, it becomes possible to obtain the effect of SERS even for a single molecule [3].

Two factors of enhancement in SERS should be taken into account, namely, the chemical and electro-

\footnotetext{
1 This work was reported at the XXII International SchoolSeminar of Galyna Puchkovska "Spectroscopy of Molecules and Crystals" (20-27 September 2015).
}

ISSN 2071-0194. Ukr. J. Phys. 2016. Vol. 61, No. 9 
magnetic enhancement factors. A change in the Raman cross section due to a change in the environment of the molecule is called the chemical or electronic contribution to the Raman enhancement. A much more important factor in the total enhancement is an increase of the electromagnetic field that is called the electromagnetic enhancement factor. This factor reflects a change of the spatial distribution of the electromagnetic field due to the excitation of surface plasmons. The effect have been observed on rough metal surfaces, especially on surfaces with periodic nanostructures. The random rough metal surface can be imagined as a set of simplified submicron metal particles, such as spheres of arbitrary size (less than the wavelength of light) randomly distributed over the surface of a metal.

The size of these particles must be sufficiently large compared with the interatomic distance, so they had a free electron gas. Localized oscillations of the electron density of ellipsoids have oscillating dipole moments interacting with one another through the Coulomb field creating a collective mode. Consequently, the rough surfaces must have a maximum optical absorption under the excitation of the longitudinal and transverse modes of plasmon oscillations. It was found that these resonances arising from the excitation of longitudinal collective electron oscillations in the metal islands are localized surface plasmons.

In case of absorbed molecules at the surface of metal particles, the resonant enhanced local field $E_{\text {loc }}$ (at the frequency of the incident light wave $\omega_{i}$ ) acts on them. The oscillations of molecular dipoles, which are excited by field $E_{\text {loc }}$, at the Stokes frequency $\omega_{s}=\omega_{i}-\Omega$ (where $\Omega$ is the frequency of intramolecular vibrations active in Raman scattering) excite, in turn, the collective modes of electronic oscillations in the surface structures due to its Coulomb field that emit and consequently enhance the emission of molecular dipoles at a frequency $\omega_{s}[1,4]$. Thus, the submicron metal structures localized on the surface act as energy accumulators and efficiently enhance both incident and scattering radiation, which leads to an effective increase of the Raman cross section.

The main aim of this work is to study the linear and nonlinear amplification processes through the effective excitation of plasmons generated in the laserinduced metal structures.

\section{Experimental Details and Discussion}

Silver is chosen for the study because a large gain of the field is expected exactly for this metal, which is determined by the ratio of the real and imaginary parts of the dielectric constant. Moreover, the resonance frequency of a surface plasmon is in the visible range. A Ti:sapphire femtosecond laser with a wavelength of $800 \mathrm{~nm}$, pulse duration of $130 \mathrm{fs}$, pulse frequency of $1 \mathrm{kHz}$, and average output power of $800 \mathrm{~mW}$ has been used for the formation of nanostructures on the silver surface. The variation of the laser power density is achieved by changing the distance between the metal surfaces and focusing lens. Thus, under the influence of laser irradiation, the periodic structures resembling quasiperiodic diffraction gratings have been obtained on the silver surface.

One of the possible mechanisms of formation of these structures is associated with the partial conversion of laser energy into a surface wave due to the diffraction from existing periodic lattices [5]. A resonant grating is formed by random inequalities that, in one or another degree, are inherent to any surface. While propagating, the surface polaritons interfere with laser radiation, and, as a result, a standing wave is formed. Under a sufficient excitation intensity, the irregular heating of the surface occurs. This process causes an increase of the height of the res-

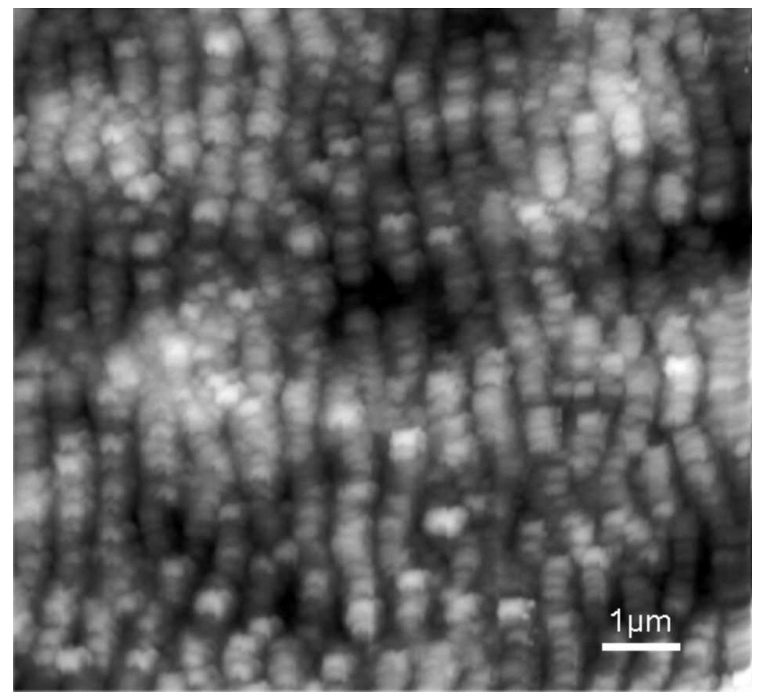

Fig. 1. AFM-image of the Ag surface after the laser irradiation by a femtosecond laser 


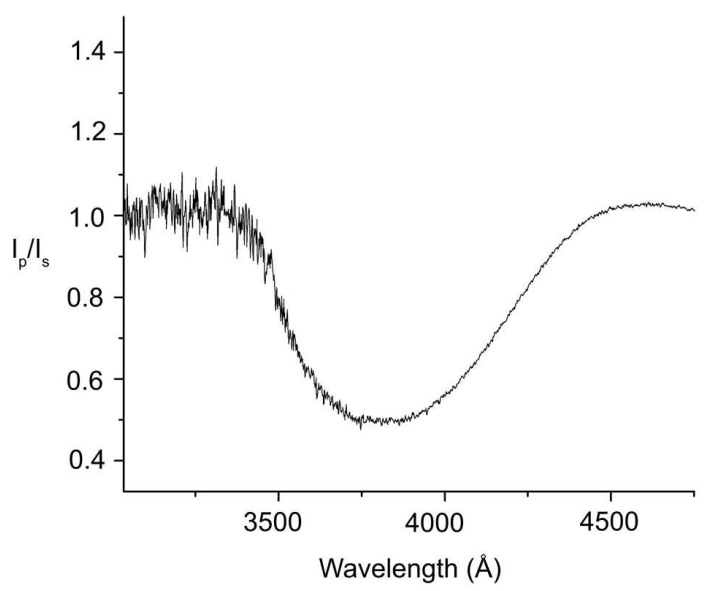

Fig. 2. Ratio of the spectra intensity of light reflected from the structured surface with the $p$ - and $s$-polarizationa

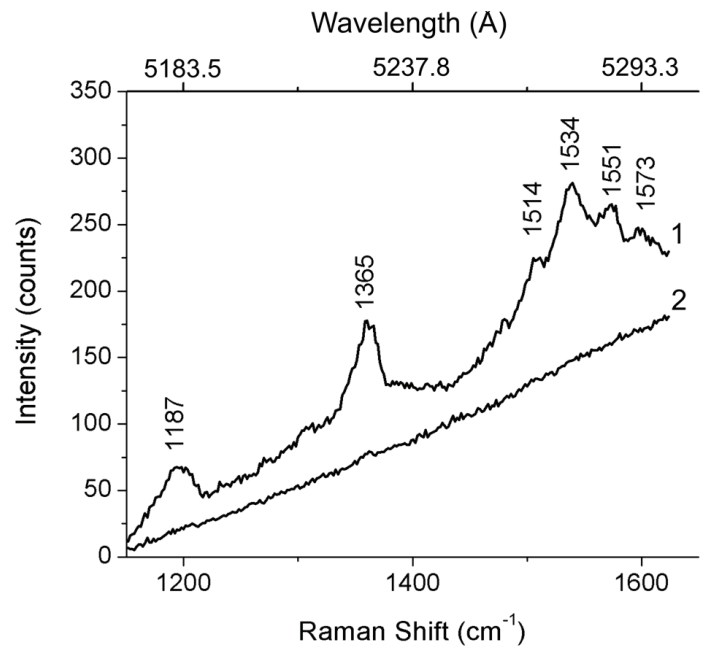

Fig. 3. Raman spectra of R6G under the $\mathrm{Ar}^{+}$-laser excitation $\left(\lambda_{\text {exc }}=488.0 \mathrm{~nm}\right)$ on the laser-induced Ag structure (1), and on the polished surface (2)

onance relief due to the thermal processes and the possible surface diffusion on surface [6]. We have studied the morphology of treated surfaces by using atomic force microscopy (AFM) (Fig. 1). The analysis of AFM data allowed us to determine the value of period of the obtained structure in the interval 500$600 \mathrm{~nm}$.

Figure 2 shows the ratio of light intensities reflected from the laser-structured surface with different polarizations. The measurement has been performed with a spectrometer MDR-3 in geometry at a fixed incidence angle of $45^{\circ}$. Surface plasmon polaritons are excited only by one component of the incident wave, the electric field vector of which is perpendicular to the plane of the sample, i.e., the $p$-polarization. Therefore, it should be observed as a dip in the scattering spectrum at certain wavelengths that are responsible for the excitation of surface plasmons. In turn, the reflectivity of a wave with the $s$-polarization should not be changed. Thus, the ratio of reflection spectra for light of the $p$ - and $s$-polarizations demonstrates a dip caused by the excitation of surface plasmon polaritons with the $p$-polarization.

To investigate the presence of nanostructures on the laser-treated surface and their influence on the Raman scattering, the Raman spectra of Rhodamine 6G dye (R6G) on different substrates - with and without laser-induced structure - have been compared.

Measurements have been performed at room temperature with a double grating spectrometer DFS24. The Raman spectra of Stokes scattering are obtained under an excitation wavelength of $488 \mathrm{~nm}$ in the 45-degree geometry. The increase of the intensity to larger wavenumbers in both spectra in Fig. 3 is due to the photoluminescence of $\mathrm{R} 6 \mathrm{G}$, which is located in the yellow-orange spectral range. It should be noted that the intensity of Raman lines enhanced at the structured surface (Fig. 3, curve 1) becomes comparable with the intensity of the photoluminescence band. This indicates the large Raman enhancement factor.

By comparing the spectra, it can be concluded that the Raman spectra of laser-induced structures feature the enhanced photoluminescence intensity and an enhancement of Raman bands characteristic of R6G, which demonstrate good coincidence with the Raman lines amplified with silver nanoparticles [7]. The highenergy lines in vicinities of $1365 \mathrm{~cm}^{-1}$ and $1534 \mathrm{~cm}^{-1}$ corresponding to aromatic longitudinal oscillations of $\mathrm{C}-\mathrm{C}$ of $\mathrm{R} 6 \mathrm{G}$ are readily observed on the structured surface. From the analysis of the ratio of the intensities of Raman bands on the structured and flat surfaces, the gain coefficient was estimated. It equals 20. Summarizing the obtained results, we can conclude that the formation of micro- and nanostructures on the metal surface under the influence of a powerful femtosecond irradiation causes the surface enhancement of Raman scattering, and the nature of this Raman signal amplification is determined by the existence of the resonant excitation of surface plasmons.

ISSN 2071-0194. Ukr. J. Phys. 2016. Vol. 61, No. 9 


\section{Summary}

Laser-induced structures on the surface of silver have been obtained under a powerful femtosecond laser irradiation of the metal surface. The morphology of the obtained structure is a quasigrating with a period in the interval 500-600 $\mathrm{nm}$ with smaller grains of tens of nanometers in size. The excitation of surface plasmons has been clearly demonstrated by the reflection spectroscopy. The effect of surface enhancement of the Raman scattering of Rhodamine $6 \mathrm{G}$ dye adsorbed on these structures has been discovered, and the enhancement coefficient is equal to 20 .

The samples were prepared at the Femtosecond Laser Center for collective use at the Institute of Physics, National Academy of Sciences of Ukraine. The authors thank E.E. Melnichuk (Taras Shevchenko National University of Kyiv) for carrying out the AFM measurements of the samples. The publication is based partially on the research provided by the grant support of the State Fund for Fundamental Research (project F64/38-2015).

1. V.I. Emel'yanov and N.I. Koroteev, Giant Raman scattering of light by molecules adsorbed on the surface of a metal, Soviet Physics Uspekhi 24, 864 (1981).

2. K. Kneipp, Surface-enhanced Raman scattering, Physics Today 60(11), 40 (2007).

3. A.M. Michaels, M. Nirmal, and L.E. Brus, Surface enhanced Raman spectroscopy of individual Rhodamine $6 \mathrm{G}$ molecules on large Ag nanocrystals, J. Am. Chem. Soc. 121, 9932 (1999).
4. J.C. Maxwell-Garnett, Colours in metal glasses and in metallic films, Phil. Trans. of the Royal Soc. of London. Ser. A 203, 385 (1904).

5. A. Weck, T.H.R. Crawford, A. Borowiec, D.S. Wilkinson, and J.S. Preston, Femtosecond laser-based fabrication of a new model material to study fracture, Appl. Phys. A: Mater. Sci. Process. 86, 55 (2007) [DOI: 10.1007/s00339006-3730-x].

6. A. Weck, T.H.R. Crawford, D.S. Wilkinson, H.K. Haugen, and J.S. Preston, Ripple formation during deep hole drilling in copper with ultrashort laser pulses, Appl. Phys. A: Mater. Sci. Process. 89, 1001 (2007).

7. J. Cyriac, G. Li, and R.G. Cooks, Vibrational spectroscopy and mass spectrometry for characterization of soft landed polyatomic molecules, Anal. Chem. 83, 5114 (2011) [DOI: $10.1021 / \mathrm{ac} 200118 \mathrm{f}]$.

Received 31.07.15

С. Вовденко, I. Дмитрук,

Н. Березовсъка, С. Кутовий, А. Калюжний,

Н. Зубрилін, О. Домбровсъкий

ЛАЗЕРНО-ІНДУКОВАНІ КВАЗІПЕРІОДИЧНІ

МЕТАЛЕВІ СТРУКТУРИ ДЛЯ ЕФЕКТИВНОГО

ЗБУДЖЕННЯ ПОВЕРХНЕВИХ ПЛАЗМОНІВ

$\mathrm{P}$ е $з$ ю м е

Мікро- та наноструктури на поверхні срібла були сформовані під дією випромінювання титан-сапфірового фемтосекундного лазера. Сформовані структури були досліджені за допомогою атомно-силової мікроскопії, діаграм розсіяння світла та оптичної спектроскопії. Досліджено вплив поверхневих плазмонів на цих структурах на комбінаційне розсіяння світла від барвника родамін $6 \mathrm{G}$ (Rh6G). Було виявлено підсилення деяких ліній спектра у 20 разів, що свідчить про перспективність такого методу приготування підкладок для поверхневого підсилення комбінаційного розсіяння світла. 